ESUKA - JEFUL 2010, 1 - 1: $41-56$

\title{
VADJA KIRJAVIISIST JA SÕNALOOMEST
}

\author{
Enn Ernits \\ Eesti Maaülikool
}

Kokkuvõte.Võimalikult efektiivse kirjakeele loomiseks tuleb lahendada järgmised põhiprobleemid: 1) valida sobiv(ad) murdetaust(ad), 2) kehtestada keele normid, 3) luua kirjaviis ning 4) kohaldada keel vastavaks tänapäeva kultuuri- ja ühiskonnanõuetele (Tauli 1968: 19). Nimetatud küsimuste lahendamisel võib lähtuda nii keelekorralduse üldpõhimõtetest kui ka teiste läänemeresoome keelte (eesti, soome, võru ja vepsa kirjakeele) korraldamise kogemustest. Pisikeele probleeme on tänapäeval soovitatav lahendada võimalikult paindlikult. Siinkirjutaja eelistab võtta vadja kirjakeele põhjaks Kattila murde, kuid ei välista teistegi murrete kasutamist. Vähemalt esialgu tuleks kirjakeelt normeerida nii vähe kui võimalik. Soovitatav on tarvitada maksimaalselt foneemilist kirja, milles oleksid $c, \check{c}, \check{s}, \check{z} ; \tilde{o}, \ddot{a}, \ddot{o}, \ddot{u} ; d, \dot{n}, \dot{r}, \dot{z}, t$. Sandhi tuleks jätta tähistamata. Keelt on vaja rikastada tänapäevaste mõistetega, kusjuures sõnavara saab luua nii oma ressursside kui ka naaberkeelte leksika varal. Omasõnu luuakse põhiliselt liitmise ja sufiksite abil tuletamise teel, näiteks čehsi-škoulu 'keskkool', nimezikko 'nimekiri, nimestik' (< nimi 'nimi').

Märksõnad: murdetaust, keelenormid, kirjaviis, sõnaloome, keelekorraldus, vadja keel, läänemeresoome keeled

Abstract. The orthography and formation of words of the Votic language.To create an effective literary language, it is necessary to solve the following main problems: 1) selecting suitable dialect area(s); 2) establishing linguistic standards; 3) developing orthography; and 4) adapting the literary language to modern linguistic and cultural demands (Tauli 1968: 19). In solving these problems with regard to the Votic language, language planners can start from both general principles of language planning and the planning experiences of other Balto-Finnic literary languages, such as Estonian, Finnish, Võro and Veps. Today it is advisable to resolve the planning problems of minority languages as flexibly as possible. The author favours the Kattila dialect as the background for the written language, but does not exclude the use of other Votic dialects for this 
purpose. In the initial period of the Votic literary language at least there is no real need to determine strong norms. It is strongly advised that consistent use be made of a phonological writing system using the letters $c, \check{c}, \check{s}, \check{z}, \tilde{o}, \ddot{a}, \ddot{o}, \ddot{u} ; d^{\prime}, \dot{n}, \dot{r}, \dot{z}$ and $t^{\prime}$. There is no need to designate the sandhi in the script. The language should be enriched with modern concepts where possible, with the creation of new lexis based on actual words and those borrowed from neighbouring languages. The formation of words is mainly the result of compounding and derivation, for example čehsi-škoulu 'secondary school' and nimezikko 'list' (< nimi 'name').

Keywords: dialect background, linguistic standards, orthography, word formation, language planning, Votic language, Balto-Finnic languages

\section{Sissejuhatuseks}

Viimase rahvaloenduse andmeil elas 2002. aastal Vene Föderatsioonis 72 inimest, kes pidasid end vadjalasteks. Kõnelejaid oli aga mitu korda vähem. Votoloog Heinike Heinsoo (2007: 52) väitel oskas vadja keelt hästi vaid kümmekond vanakest. Tänapäeval kasutatakse seda üksnes teadlaste küsimustele vastates veel Leningradi oblasti Kingissepa rajooni kahes külas, nimelt Jõgõperäl (vn Краколье) ja Luuditsas (vn Лужицьь) (Agranat 2007: 8), kusjuures keeletarvitus on puhuti isuri- ja venesegune.

Pärast Nõukogude Liidu lagunemist tekkis Vadjamaal ja Peterburis liikumine, mille harjal loodi ka vadja kirjakeel. Liikumine oli seotud kahe võtmeisikuga: kultuuri üritas äratada vadjalasega abielus olev inseneriharidusega Tatjana Jefimova ning kirjakeele lõi filoloogiakandidaat Mehmet Muslimov. Viimane hakkas 1994. aastal Peterburis korraldama vadja keele kursusi, millel osales nii vadja juurtega inimesi kui ka teisi. Hiljem hakati keelt ja kultuuri aluseid õpetama ka Jõgõperä keskkooli koduloo fakultatiivtundides. Peterburi folkmuusika portaalis on praegugi üleval viis õppetundi, mille on kirjutanud M. Muslimov (vt lähemalt Ernits 2006a). Plaanis oli vadja aabitsa koostamine, kuid sellest pole praegu enam midagi kuulda, sest vadja keelt hästi valdav $M$. Muslimov on koondanud oma tähelepanu mujale. Kuuldavasti on ka $\mathrm{T}$. 
Jefimova loobunud vadja kultuuri arendamisest. Seega on vadja liikumine kas hääbumas või juba hääbunudki. See muidugi ei välista uusi arenguid tulevikus.

2004. aastal ilmus esimene vadja ilukirjanduslik raamat (tõsi küll, kahes keeles), mis polnud teaduslikus transkriptsioonis, vaid vadja kirjaviisis. See on 40-leheküljeline muinasjutukogumik „Vađđa kaazgõt. Водские сказки“. Tegelikult on see teine väljaanne, sest esimene oli tõenäoliselt arvutipaljundus, millel puuduvad nii trükiandmed kui ka ISBN number. Esimeses väljaandes olid muinasjuttude murdeiseärasused säilitatud, ent teises kogumikus on nad tõlgitud ainukesse elavasse Jõgõperä murdesse (vt Ernits 2006b). Tuntavaid erinevusi leidub ka kirjaviisis.

Siinkirjutaja loodab, et vadja pisikirjakeele kasutusevõtt on tänapäeva postmodernistlikus ühiskonnas mõttekas, sest tunnistatakse väärtushinnangute suhtelisust, mis võimaldab hõlpsamini rakendada enesemääramisõigust nii väikerahvastele kui ka üksikisikutele. Kunagi jättis siinkirjutajale sügava mulje Paul Ariste (1977) artikkel korni keele velmamisest. Vadja keele puhul on olukord teine - kirjakeelt pole õieti olnudki, kuid keelt veel siiski osatakse, ent oodatavad tulemused võiksid olla ligikaudu samad. Eesmärgiks tuleks seada, et kõnekeel jääks püsima ning ilmuks õpikuid, ajakirju, lugemikke jm kirjasõna. Soovitatav oleks ka huviliste ring, kes kasutaks omavahel keelt nii suuliselt kui ka kirjalikult. Seega tuleks vadja keelele soovida muutunud olukorras jätkusuutlikkust veel tulevikuski.

\section{Keelekorralduse printsiibid ja põhiprobleemid}

Keel peab olema arusaadav, ökonoomne ja esteetiline. Selle hindamiseks ja korraldamiseks on keelekorraldusteoreetik Valter Tauli sõnastanud 17 printsiipi, sh neli selguse, viis ökonoomia ja kaheksa esteetilisuse huvides, näiteks „Mida suurem on võimalus tähenduslikuks väärmõistmiseks, seda suurem peab olema väljendi erinevus“ (S 4), „Väljend peab olema võimalikult lühike“ (E 2) . Osa põhimõtteid on üksteisega paratamatult vastuolus, mistõttu põhimõtete kohaldamiseks lisati veel kuus rakendusprintsiipi. Peale selle tuletas V. Tauli põhiprintsiipide baasil veel kaks eriprintsiipi 
morfoloogia ja üheksa sõnavara hindamiseks ja arendamiseks, nt „Kui kaht tähendust tuleb sageli tarvitada samas kontekstis, siis nende jaoks peavad olema eri sõnad" (L 6; vt Tauli 1968: 29-39, 50, 94-118). Kahtlemata tuleb asjaomaseid printsiipe tõsiselt arvestada ka vadja keelekorralduses.

Võimalikult efektiivse kirjakeele loomiseks tuleb lahendada järgmised põhiprobleemid: 1) valida $\operatorname{sobiv(ad)}$ murdetaust(ad), 2) kehtestada keele normid, 3) luua kirjaviis ning 4) kohandada keel vastavaks tänapäeva kultuuri- ja ühiskonnanõuetele (Tauli 1968: 19). Viimane nõuab eelkõige sõnavara arendamist. Nimetatud küsimuste lahendamisel võib lähtuda nii keelekorralduse üldpõhimõtetest kui ka teiste läänemeresoome keelte (eesti, soome, võru ja vepsa kirjakeele) korraldamise kogemustest.

\section{Murdetaust ja keelenormid}

Pisikeele probleeme on soovitatav tänapäeval lahendada võimalikult paindlikult. Kõne- ja kirjakeeleks sobib aktsepteerida iga kasutaja murret või murrakut, mis vadja keeles pole olnudki nii erinevad. Siinkirjutaja on traditsioonilise läänemurde jaganud Kattila ja Jõgõperä murdeks, sest mõlemal on ühepalju erinevusi ida- ehk Kabrio murdest (Ernits 2005: 77). Siinkirjutaja eelistab Jõgõperä murdele 1980. aastate alguses hääbunud Kattila kõnepruuki, milles oli suhteliselt vähem võõrmõjusid. Seevastu vadja keele Jõgõperä murre ja isuri keele Alam-Lauga murre on puhuti üsna sarnased, mis muidugi ei tähenda, et esimest (ja miks ka mitte teist) ei võiks edasi arendada. Nad on ju omavahel võrreldavad samal moel kui vepsa ja lüüdi keel. Kirjakeelena võiks kasutada ka Kabrio murret, ent ülejäänud murrete, nagu nn kreevini keele kasutusevõtt eeldaks liiga paljude hüpoteetiliste sõnakujude loomist.

Mis puutub vadja keele normimisse, siis seda tuleks teha vähemalt esialgu nii vähe kui võimalik, et mitte peletada normijäikusega huvilisi eemale. Lubada tuleks kõiki keeles käibinud paralleelvorme jms. Kõne alla võiks tulla ka mõne uue tuletusliite kasutusevõtt. 
Vadja kirjaviisist ja sõnaloomest 5

\section{Kirjaviis}

Ideaalilähedase kirjaviisi rakendamisel tuleks arvestada põhiliselt kolme printsiipi: 1) kirjas peaksid olema vastavuses foneemid ja neid tähistavad märgid (grafeemid), s.o kiri olgu foneemiline, 2) iga foneem tähistatakse ühe grafeemiga, 3) ortograafia põhineb isoleeritud sõna hääldusel normaalses kõnes (morfeemi muutumatuse printsiip), kusjuures kiirkõnehäälikud ja sandhi jääksid kajastamata (Tauli 1968: 160-166).

\subsection{Ajalooline ülevaade kirjaviisidest}

Aegade vältel on vadja tekstide kirjapanekul kasutatud mitut ladina ja slaavi tähestikul põhinevat moodust. Vaadelgem neid lühidalt kronoloogiliselt, kuid üksteisest lahus.

Esimese vadja teksti, nimelt ühe rahvalaulu jupi avaldas 1783. aastal sakslasest Narva pastor Fr. L. Trefurt (SKVR IV 673, nr 4593). See on talletatud saksapärases kirjaviisis ladina tähtedega, vadja keelt oskamata, mistõttu teksti rekonstrueerimine on nõudnud mitme uurija jõupingutusi (Ariste 1956 ja Winkler 1993). Kasutatakse $w$-d (awita, ukv ${ }^{1}$ avita 'avita') ja tähekombinatsiooni tsch (tschen, ukv čen 'kes'). Õ-häälikut on tähistatud samal viisil nagu $\ddot{a}$-d (saenad 'sõnad', vrd pael, ukv pääll(ä) 'peal') või siis $o$-na (toisae, ukv tõisõ õ 'teise').

19. sajandil on vadja rahvaluulet peale ühe erandi noteerinud vaid soomlased (tabelid 1 ja 2). Esialgu olid kirjapanekud üsna vigased ja üksikute häälikute tähistamise poolest ebajärjekindlad. Rahvaluuletalletajatest oli esimene A. J. Sjögren, kes pani 1831. aastal kirja kolm laulu (SKVR IV 674-675, nr 4594-4596) $)^{2}$. Ta tähistas $\check{c}$-häälikut täheühendiga tsch (tschylve, ukv čülve 'külbe, vihtle'), ü-d y-na (ennetyttö

1 Lühend ukv tähistab siinkohal ja edaspidi käesoleva artikli autori kirjaviisi.

2 Viiteaparaadi ülekoormamise vältimiseks on enamasti piirdutud SKVR-le viitamisega. 
'ematütar'), $\tilde{o}$-d aga mitmeti. Selle vasteks oli A. J. Sjögrenil esimeses silbis kord $e$ (vetab, ukv võtab 'võtab'), kord $\ddot{o}$ (töine, ukv tõinõ 'teine'), kord o (jogessä, ukv jõgõssa 'jõest'), järgsilbis aga $e$ (naine, ukv nainõ 'naine') ja a (kölmad, ukv kõlmõd 'kolm'). Kirjapanekutes ei kajastunud $z$ ega sandhi, nt (lachsed töiväd, fon lahzõt tõivaD 'lapsed tõid', tyttäret Juga, fon tüttäred Jugaa 'tütred Joa'). Võimalik, et A. J. Sjögren eristas tavalise $h$ kõrval bilabiaali $\varphi$, millele näib osutavat üsna järjekindlalt grafeemilise ch (ychsi, ukv ühsi 'üks', lachsed, ukv lahzõd 'lapsed') ja $h$ (vihta 'viht') vahetegemine.

Tabel 1. Vadja täishäälikud 19. sajandi kirjapanekutes ${ }^{3}$

\begin{tabular}{|c|c|c|c|c|}
\hline $\begin{array}{l}\text { Uurija nimi ja } \\
\text { kirjapaneku aasta }\end{array}$ & $\begin{array}{l}\text { Esisilbi } \\
\text { /õ/ }\end{array}$ & $\begin{array}{l}\text { Järgsilbi } \\
\text { /õ/ }\end{array}$ & /ü/ & $\begin{array}{l}\text { Järgsilbi } \\
\text { pikkvokaalid } \\
\text { (/aa/ jne) }\end{array}$ \\
\hline A. J. Sjögren (1831) & $\mathrm{e}, \mathrm{o}, \ddot{\mathrm{o}}$ & $\mathrm{e}, \mathrm{a}$ & $\mathrm{y}$ & aa \\
\hline $\begin{array}{l}\text { G. Rein } \\
\text { (1830ndate algus) }\end{array}$ & $\mathrm{e}, \mathrm{o}, \ddot{\mathrm{a}}$ & $\mathrm{E}$ & $\ddot{\mathrm{u}}, \mathrm{y}$ & aa \\
\hline $\begin{array}{l}\text { A. Reguly } \\
(1841)\end{array}$ & $\mathrm{o}, \ddot{\mathrm{o}}$ & $e, o e, \ddot{o}, a$ & $\mathrm{y}$ & a \\
\hline $\begin{array}{l}\text { E. Lönnrot } \\
\text { (1844)D. }\end{array}$ & $\mathrm{o}, \tilde{\mathrm{o}}, \breve{\mathrm{o}}$ & $\mathrm{E}$ & $\mathrm{y}$ & a, aa \\
\hline $\begin{array}{l}\text { D. E. D. Europaeus } \\
(1853)\end{array}$ & $\tilde{\mathrm{o}}(\mathrm{b})^{4}$ & e, Ы, (a, ö) & $\mathrm{y}$ & aa \\
\hline $\begin{array}{l}\text { A. Ahlqvist } \\
(1854-1855) \\
\end{array}$ & $\tilde{\mathrm{o}}$ & e, õ, (ë) & $\ddot{\mathrm{u}}$ & $\hat{a}$ \\
\hline $\begin{array}{l}\text { O. Groundstroem } \\
(1861)\end{array}$ & $\mathrm{o},(\mathrm{e})$ & $\mathrm{e}$ & $\mathrm{y}$ & $\mathrm{a}(\mathrm{aa})$ \\
\hline $\begin{array}{l}\text { A. A. Borenius } \\
(1877)\end{array}$ & $\tilde{\mathrm{o}}$ & $\mathrm{e},(\ddot{\mathrm{e}})$ & $\mathrm{y}$ & aa \\
\hline $\begin{array}{l}\text { O. A. F. Mustonen } \\
\text { (1882) }\end{array}$ & $\tilde{\mathrm{o}}$ & $\tilde{\mathrm{o}}$ & $\ddot{\mathrm{u}}$ & aa \\
\hline
\end{tabular}


Tabel 2. Vadja kaashäälikud 19. sajandi kirjapanekutes

\begin{tabular}{|c|c|c|c|c|c|c|}
\hline $\begin{array}{l}\text { Uurija nimi ja } \\
\text { kirjapaneku aasta }\end{array}$ & $/ \mathrm{c} /$ & /čl & $/ \mathrm{d}^{\prime} /$ & /hs/ & $|z|$ & /v/ \\
\hline $\begin{array}{l}\text { A. J. Sjögren } \\
(1831)\end{array}$ & ts & tsch & $\mathrm{dj}$ & chs & $\mathrm{s}$ & $\mathrm{v}$ \\
\hline $\begin{array}{l}\text { G. Rein } \\
\text { (1830ndate algus) }\end{array}$ & ts & $\mathrm{k}, \mathrm{tsch}$ & di & $\mathrm{ks}, \mathrm{x}$ & $\mathrm{s}$ & $\mathrm{v}$ \\
\hline $\begin{array}{l}\text { A. Reguly } \\
(1841)\end{array}$ & $\begin{array}{l}\mathrm{cz} \\
\mathrm{tz}\end{array}$ & tsch & gy & hs, s & $\mathrm{z}$ & $\mathrm{v}$ \\
\hline $\begin{array}{l}\text { E. Lönnrot } \\
(1844)\end{array}$ & ts & $\begin{array}{l}\text { ts, tsch, } \\
\mathrm{kj}, \mathrm{k}, \\
\mathrm{ksj}, \mathrm{tsj}\end{array}$ & $\mathrm{dj}$ & ss & $\mathrm{s}$ & $\mathrm{v}, \mathrm{w}$ \\
\hline $\begin{array}{l}\text { D. E. D. Europaeus } \\
(1853)\end{array}$ & ts & $\check{c}$ & $\mathrm{dj}$ & hs & $\mathrm{S}$ & $\mathrm{v}$ \\
\hline $\begin{array}{l}\text { A. Ahlqvist } \\
(1854-1855)\end{array}$ & ts & $c^{\prime}$ & d' & hs & $\mathrm{z}, \mathrm{s}$ & w \\
\hline $\begin{array}{l}\text { O. Groundstroem } \\
(1861)\end{array}$ & ts & $\mathrm{k}$ & $\mathrm{dj}$ & hs & $\mathrm{s}$ & $\mathrm{V}$ \\
\hline $\begin{array}{l}\text { A. A. Borenius } \\
\text { (1877) }\end{array}$ & ts & c & $\mathrm{d}^{\prime}$ & hs & $\mathrm{s}, \mathrm{z}$ & $\mathrm{V}$ \\
\hline $\begin{array}{l}\text { O. A. F. Mustonen } \\
(1882)\end{array}$ & ts & $\mathrm{t} \square$ & $d^{\prime} j$ & hs & $\begin{array}{l}\mathrm{Z}, \\
\text { (s) }\end{array}$ & $\mathrm{V}$ \\
\hline
\end{tabular}

Prof Gabriel Reini kirjapanekud 1830ndate algusest on samuti üsna ebatäpsed, sisaldades ohtrasti soomepärasusi (SKVR IV 676-685, nr 4597-4605). Käsikirjas paralleelselt esitatud tekst, mille autoriks peetakse pastor J. J. Groundströmi, püüab G. Reini oma parandada, kuid tulemusteta. Noore ungarlase Antal Reguly kirjapanekud pole algaja kohta sugugi kehvad (vt Reguly 1958). Ootuspärane on nentida, et d'd' vasteks on esitatud ungaripärane ggy (meggye, ukv med'd'ee 'meie'). Nii ungari vana kirjaviisi tähekombinatsioon cz kui ka tz tähistavad c-d (oczallas, ukv ocallaz 'sinu otsal'; neitzyelli, ukv neittsüelle 'neiukesele').

Ka Elias Lönnroti rahvalaulunoteeringud pole vaatamata sellele, et vadja keel oli talle lähedasem kui ungarlasele, kuigi järjekindlad (vt SKVR IV 686-719, nr 4606-4635). Tavalistes regilauludes on E. Lönnrotil $v$-hääliku vasteks $v$ (veejä 'viija'), 
kuid itkudes kohati $w$ (walkea, ukv valkõa 'valge'; vt Haltsonen 1958). Rahvalauluainestikku 1853. aastal kogunud D. E. D. Europaeus (vt Haltsonen 1957: 31-45) oli suhteliselt terava kõrvaga. Tähelepanuväärne on venepärase $\tilde{o}$ eristamine. Selle on ta märkinud $b l$ kujul nii esisilbis pikkvokaali puhul (mbleka 'mõõga') kui ka järgsilbis (lipbıa 'libe'), ent tavalisemalt siiski $e$-na (uhse, ukv uhzõ ó 'ukse'). Senistest täpsemad on August Ahlqvisti aastatel 1854-1855 tehtud kirjapanekud (vt SKVR IV 720-732, nr 4636-4659 ja Ahlqvist 1856). Siiski esineb tal ka ebatäpsusi. Eriti hakkab silma järgsilbi $\tilde{o}$ tähistamine kolmel viisil: $e^{-}, \tilde{o}$ - ja paaril juhul $\ddot{e}$-na (iwuhset, ukv ivuhsõd 'juuksed', kuhõ 'kuhu', wassaelëb, ukv vassaõlõb 'vastab'). Nagu varasemadki kirjapanijad, ei pööra nimetatud autor tähelepanu sandhinähtusele. Tal esineb ka üleliigne ülakoma lõpukao tähisena järgsilbi pikkvokaali järel (vt VKS 1: 16). Analoogiliselt $c^{\prime}$-ga on ta tähistanud ka $\check{s}$-hääliku $\left(s^{\circ}\right)$.

Üliõpilane Oskar Grounstroem käis Vadjamaal rahvalaule kogumas 1861. aastal (vt SKVR IV 733-738, nr 46604679). Paraku jäi talle enamik vadja iseärasusi märkamata. A. A. Boreniuse kirjapanekutega võib üldiselt rahul olla (vt SKVR IV 739-746, nr 4680-4699). Omapärane on čchääliku märkimine $c$ kujul (cülä, ukv čülä 'küla'). O. A. F. Mustoneni (1883) omapäraks on 1882. aastal esmakordselt Jõgõperält kogutud ainese põhjal alloleva kaarega $t$ kasutamine hääliku $\check{c}$ tähistamiseks.

Alates E. N. Setäläst, kes viibis Vadjamaal 1889. ja 1910. aastal (vt SKVR IV 748 jj, nr 4702 jj) algab vadja keeles suhteliselt täpse soome-ugri transkriptsiooni kasutamine. Mõnevõrra erandlikud selles suhtes on Vihtori Alava kirjapanekud 1901. aastast (vt SKVR IV 751-771, nr 4710-4779). Suhteliselt hea õigekirjaga on vadjalasest õpetaja Pavo (Pavel) Tsvetkovi kiri P. Aristele 1930. aastate algusest, autor kasutas selles ladina tähestikku, sh $\tilde{o}$-d ja ťs-d (Eesti Kultuurilooline Arhiiv 330, 104:1).

Kirillitsas on vadja sõnavara ja lauluainest keelt oskamata vahendanud XVIII sajandi lõpul Fjodor Tumanski (vt Öpik 1970: 108-109, 165-189). Paraku ei saa üksnes kirillitsa tähemärkide abil kõiki vadja häälikuid edastada (Adler 1970: 191). Sama tähestikku, kuid juba varustades mõne neist täppidega ( $\ddot{a}$, $\ddot{o}$, ï) kasutas oma grammatika käsikirjas 1922. aastal vadja haritlane Dmitri Tsvetkov (2008: 6 jj). Peale selle on vene tähti 
kasutanud P. Aristega mitu keelejuhti kas oma ülestähendustes või erakirjades, sh Kikoria (Grigori) Kuzmin Pummolast, Olga Ivanova Matist, Kat'a (Jekaterina) Jovleva Kõrvõttulast, ja Kostja (Konstantin) Leontjev Liivtšüläst (Ariste 1941: 15-19, Ariste 1960: 72, 73 ja Ariste 1986: 56).

Nende kirjaviisi analüüsi jätame praegu kõrvale. Mainigem vaid, et näiteks $\mathrm{K}$. Kuzmin ei tarvitanud häälikute vahendamisel ühtki lisamärki. Nii pikad vokaalid kui ka konsonandid tähistas ta ühekordselt, näiteks Милизед влливад вадялайсил пыло рисат?, ukv Millized õlivad vad'd'alaisiill põlluo-riisad? 'Millised olid vadjalastel põlluriistad?' (Ariste 1941: 17). XIX sajandi lõpukümnendil sündinud Olga Ivanova kohta nentis P. Ariste järgmist: "Tema on ainus teadaolev vadjalane, kes teeb enesele märkmeid vadja keeles ning saadab keeleoskajaile vadjakeelseid kirju. Vadja keelt kirjutab ta vene keele õigekirjutuse järgi." (Ariste 1960: 72).

Kokkuvõtteks XIX sajandi vadja kirjaviiside kohta nenditagu, et need sõltusid eelkõige kirjapaneja rahvusest, seega emakeele kirjaviisist. Probleemseks osutus, nagu seda võis juba eeldadagi, emakeeles puuduvate hääldusjoonte, näiteks soomlastel $\tilde{o}$ ja $z$ tähistamine. Seepärast jääb toonastest kirjapanekutest üpris kirev üldmulje. Sageli esineb uurijatele harjumatute häälikute valesti tajumist. Vene kultuuriruumiga kohanenud isikud (v.a eespool mainitud P. Tsvetkov) on aegade jooksul kasutanud suurema või vähema eduga üksnes kirillitsat, mis aga andis vadja keelt edasi üsnagi ebatäpselt.

Soome-ugri transkriptsioonist on peaaegu loobutud ning eri aegade kirjapanekuid on ühtlustatud 1990. aastal ilmuma hakanud mitmeköitelises „Vadja keele sõnaraamatus” (vt VKS 1: 14-17). Mittefonoloogiliste joontena on säilitatud kirjapanekute $\eta$ (nt henki 'hing; vaim') ja kohatine laensõnade $\chi$ ( renni 'mädarõigas'). Sõnaraamatus on kirjapanekute $c$ ja $c$ siinkirjutaja meelest asjata asendatud $t s$ ja $t \check{s}$-ga, nt kuttsumizôlta 'kutsumiselt' ja tšivi 'kivi' kuccumizõlta ja čivi asemel. Poolpikkade häälikute tähistamisel kasutatakse vaid erandjuhtudel eri märki, nt Mati ja Kõrvõttula murrakute ning Kabrio murde lühialguliste geminaatkonsonantide korral lühidusmärgiga (kaarega) geminaadi esikomponendi kohal. Sõnaraamatu keelenäidetes on arvestatud sandhit. Arvestades asjaomase sõnaraamatu eesmärke (vt VKS 1: 10), ei saa talle kirjaviisi osas etteheiteid teha. 


\subsection{Muslimovi kirjaviis ja selle täiendused}

Eespool nimetatud vadja muinasjuttude teises väljaandes on kasutatud ladina tähestikku mõnede lisamärkidega. Kirjaviis on üldiselt foneemiline, kuid sisaldab mõningaid soovitavaid ja ebasoovitavaid kõrvalekaldeid (vt Ernits 2006b). Järgneb lühiülevaade M. Muslimovi kirjaviisist ning soovitused selle parendamiseks.

Üksiktäishäälikute märkimine on muinasjutukogus suhteliselt järjekindel (tabel 3). Pikad vokaalid on kirjutatud kahe tähega. Ainult $y$ tuleks J. Aaviku peetud kümnele eelisele vaatamata (Tauli 1968: 165) asendada täpitäheühtluse mõttes $\ddot{u}$-ga. Problemaatiline on reduktsiooni edastamine, sest seda on seni vähe uuritud. Jõgõperä murret iseloomustab järgsilpide täishäälikute erineval määral taandumine kuni lõpukaoni välja; pikad järgvokaalid muutuvad kas poolpikkadeks või isegi lühikesteks. Muinasjuttude teises väljaandes on redutseeritud $a$ edastatud grafeemi $\tilde{o}$ abil, redutseeritud $\ddot{a}$ aga $e$ abil, näiteks maatõ < maata 'maad', lehmet 'lehmad'. Sellega on järgitud jõgõperälasest filoloogi Dmitri Tsvetkovi hääldust, mis oli teatavasti ületaotluslik (Ariste 1941: 4-5). Järgsilpide poolpikad, ent sageli ka pikad täishäälikud on muinasjuturaamatus kirjutatud ühekordselt (kultõizõ muna 'kuldse muna'). Jõgõperä murde reduktsiooniprobleemi ilma eriuurimusteta lahendada ei saa, sest tänapäeval leidub erinevusi isegi Jõgõperä ja Luuditsa murraku vahel (Agranat 2007: 38). Normaalne oleks, kui lausefoneetilised nähtused kirjas ei kajastuks, ent mõnes sõnas on lõpukadu ammu juba toimunud, näiteks ühs, kahs. Asjaomane jutt ei puuduta Kattila murde apokoopi, mis oli lausefoneetiline ja mille võib vähemalt väljaspool otsekõnet tähelepanuta jätta.

Tabel 3. Täishäälikute tähistamine $M$. Muslimovil ja soovitatavalt

\begin{tabular}{l|l|l|l|l|l|l|l|l|l} 
On & a & e & i & o & u & o & a & $\ddot{o}$ & $y$ \\
\hline Soovitatav & a & e & i & o & u & o & a & $\ddot{o}$ & $\ddot{u}$
\end{tabular}

Kaashäälikute vallas on muinasjuttude teises väljaandes ebajärjekindlusi rohkem, kuid need on hõlpsasti kõrvaldatavad. 
Süsteemitult on märgitud peenendumine, sisihäälikud ja sandhi. Tabelist 4 on näha, et peenendust on tähistatud kahel juhul erinevate lisamärkide abil, kolmandal puhul aga järgneva vokaali abil. See raskendab kirjaviisi üksikasjade meelespidamist. Seepärast on soovitatav kasutada ühesugust märkimist ülakoma abil, nagu seda tehakse näiteks võru ja vepsa keeles (vt näiteks VES, Zaiceva, Mullonen 1991). Öeldu kehtib ka vadja $\dot{r}, \dot{s}$ ja $t$ ' puhul.

Tabel 4. Peenendunud kaashäälikute tähistamine $M$. Muslimovil ja soovitatavalt

\begin{tabular}{|c|c|c|c|c|}
\hline On & $\begin{array}{c}\text { đ } \\
\text { (vađđa }\end{array}$ & $\begin{array}{c}1 \\
\text { (vil̦lla) }\end{array}$ & - & $\begin{array}{c}\mathrm{z}(\ddot{\mathrm{a}}) \\
(a z z \ddot{a} d)\end{array}$ \\
\hline Soovitatav & $\begin{array}{c}\text { d' } \\
\text { (vad'd'a } \\
\text { 'vadja') }\end{array}$ & $\begin{array}{c}\text { l' } \\
\text { (vill'a } \\
\text { 'vill') }\end{array}$ & $\begin{array}{c}\text { ń } \\
\text { (mińńa } \\
\text { 'minia') }\end{array}$ & $\begin{array}{c}\text { ź(a) } \\
\text { (aźźad } \\
\text { 'asjad') }\end{array}$ \\
\hline
\end{tabular}

Süsteemitust esineb ka afrikaatide ja sibilantide tähistuses. Ühtlustamise mõttes tuleks kasutada „katusega“ tähti (tabel 5). Tähtede $c$ ja $\check{c}$ eeliseks oleks see, et üht foneemi tähistaks üks grafeem ning mõlemad näeksid ühtmoodi välja. Niimoodi toimitakse ka tänapäeva vepsa keeles (Zaiceva, Mullonen 1991). Asjaomaseid pikki konsonante tuleks tähistada kahe märgiga, nt mecäd 'metsad', ent meccäzä 'metsas' .

Tabel 5. Afrikaatide ja sisihäälikute tähistamine M. Muslimovil ja soovitatavalt

\begin{tabular}{|c|c|c|c|c|}
\hline On & $\begin{array}{c}\text { ts } \\
\text { (metsäd) }\end{array}$ & $\begin{array}{c}\mathrm{c} \\
(\operatorname{cirj} \tilde{o} v \tilde{O})\end{array}$ & $\begin{array}{c}\text { Ş } \\
\text { (şkouluz) }\end{array}$ & $\begin{array}{c}\check{Z} \\
(\text { toož̃̃) }\end{array}$ \\
\hline Soovitatav & $\begin{array}{c}\mathrm{c} \\
\text { (mecäd } \\
\text { 'metsad') }\end{array}$ & $\begin{array}{c}c \breve{c} \\
\text { (čirjava } \\
\text { 'kirju } \\
\text { (adj)') }\end{array}$ & $\begin{array}{c}\check{s} \\
\text { (škouluz } \\
\text { 'koolis') }\end{array}$ & $\begin{array}{c}\check{Z} \\
\text { (toožo } \\
\text { 'samuti') }\end{array}$ \\
\hline
\end{tabular}

Vadja keel on sandhikeel, milles helilised konsonandid muutuvad helitute ees helituteks ja vastupidi; sõna lõpus muutuvad asjaomased häälikud aga poolhelilisteks. Muinasjuttude esimeses väljaandes oli see nähtus tähistatud 
üsna järjekindlalt, st kirjas sandhi ei kajastunud: helilised foneemid tähistati $g, b, d$, z-ga igas positsioonis, nt mettsäz $k a z v i$ 'metsas kasvas'. Teises väljaandes oli pilt muutunud üsna kirjuks: helilisi foneeme tähistati kord $g, b, d, z$-ga, kord $k, p, t$, $s$-iga, nt packaz 'määris', eb tullu 'ei tulnud', inimizet 'inimesed', mees juttõp 'mees ütleb'. Nähtuse täpseks kajastamiseks tuleks sel juhul rakendada kümmekonda tarbetut reeglit. Seepärast oleks soovitatav taastada esimese väljaande kirjaviis, millega rakenduks ka morfeemi muutumatuse printsiip. Samal põhjusel tuleks edaspidi $b, p$ ja $v$ ees hääldatava $m$-i asemel kirjutada $n$, näiteks en paa [em paa] 'ma ei pane', peren-meez [peremmeez] 'peremees'. Heliline häälik võiks säilitada ka liidete - $k o$ ja -či puhul, samuti liitsõnades.

Seega sandhi kirjas ei avaldu, vaid õige hääldamine tuleks tagada järgmise reegli abil: tähti $b, d, g, z$ loetakse üksiksõnas, pausi ees ja lause lõpus poolhelilise $B-, D-, G$ - ja $Z$ na (nagu eesti keeles), heliliste häälikute naabruses helilise $b$-, $d$-, $g$ - ja $z$-na ning helitute häälikute naabruses helitu $p$-, $t$-, $k$ - ja $s$-ina.

Mõne sõna puhul siirdub hääldamisel eelmise sõna lõppkonsonant järgmise sõna algusesse, näiteks Narvan alla [narva-nalla] 'Narva all', eb õ õ [e-bõõ] 'ta ei ole', ed ôllu [edõllu] 'sa ei ole'. Selliste sõnade hulka kuuluvad veel aika 'aeg', alaa 'alla', alta 'alt', etee 'ette', eessä 'eest', eezä 'ees', nain 'naine', oma 'oma' (Ariste 1948: 16, 22). Siiret pole ehk mõtet kirjas kajastada, sest äraõpitavate sõnade loetelu ei tule pikk.

Hõlpsama lugemise eesmärgil võib liitsõnaosised ühendada omavahel sidekriipsu varal, sest nii saab järjekindlalt kasutada kirjaviisi, mis ei kajasta sõnade ja liidete piiril tekkivaid häälikumuganemisi. Eraldamata jääks vaid -tõišš̈̈med '-teistkümmend' osised. Liidetest on sidekriipsuga ühendatud ko ja -či, nt tuli-ko? 'kas tuli?', siiz-či [siisči] 'siiski'. Nagu viimasest näitest nähtub, soosib sidekriipsu tarvitamist ka morfeemi muutumatuse printsiip.

Vähemalt õpivahendites võiks tähistada rõhu esinemist järgsilbil (peamiselt vene laenudes, kuid mõnes omasõnaski). Seda võiks teha märgiga ' täishääliku peal (o järel). Muudes trükistes tuleks rõhu märkimisest loobuda, sest vähemalt omasõnadest on võimalik anda ammendav ja suhteliselt lühike, äraõpitav loend. 


\section{Sõnaloome}

Niikaua kuni vadja keel oli elujõuline ning funktsioneeris traditsioonilises talupojakultuuris, suutis ta sõnavaraliselt areneda, kuid assimileerumise ja üha laieneva globaliseerumise tingimustes hakkas ta seni vajaminevat leksikat unustama. Seepärast on hädavajalik keele rikastamine tänapäevaste mõistetega, kusjuures tuleks lähtuda eelkõige V. Tauli (1968: 94-118) esitatud kaheksast leksikoloogiaprintsiibist. Sõnavara saab luua nii oma ressursside kui ka naaberkeelte leksika varal. Omasõnu luuakse põhiliselt liitmise ja sufiksite abil tuletamise teel.

Näiteks puudub vadja keeles eraldi sõna raamatu jaoks. Nii kiri kui ka raamat on čirja. Seepärast pakub siinkirjutaja tänapäeva olulise mõiste 'raamat' jaoks välja $z$-liitelise sõna čirjaz. Lisatagu veel teisigi tänapäeval tarvilikke liitelisi sõnu: täätüssellin 'teaduslik' (< Dmitri Tsvetkovi sõna täätüz 'teadus'), (naiz-)liikkumin '(nais)liikumine' $\quad(<\quad$ liikkua 'liikuda'), nimezikko 'nimestik' (< nimi). Tehistüvedega sõnade loomisest tuleks üldiselt hoiduda. Liitsõnu saab moodustada nii oma- kui ka võõrsõnade baasil: čehsi-škoulu 'keskkool', poolisaari pool-saari 'poolsaar', tuumi-bombi (Jõgõperä) toomibombi 'tuumapomm'. Puhuti oleks vaja laiendada sõnade tähendussfär̈ri, näiteks polüseemiline lava 'saunalava; ahjulava; kuhjalava; taimelava' (saunaa-lava, ahjoo-lava, kuhjaa-lava, taimõo-lava) võiks omandada eesti keelega sama tähenduse 'estraadilava' (estraada-lava).

Laenuallikate ja eeskujudena saab erineval määral arvesse võtta vene, soome jt keelte sõnavara. Mõnesugust vaeva nõuab laensõnade sobitamine vadja keelesüsteemi. Sõnade laenamisel võiks lubada paralleelvorme, nt konsonantlõpuliste sõnade laenamisel nii $i$ - kui ka $a$-list varianti, nagu okupantti ja okupantta 'okupant'. Laensõnades võiks eelistada rõhku esimesel silbil, nt biblioteekka 'raamatukogu' jne. Muidugi leidub uute sõnade loomisel mitmesuguseid probleeme, näiteks kas sõnade nimetavaline või omastavaline liitumine, kas lõpukadu või mitte (vt nt Ariste 1948: 130), kuid need nõuavad eeskätt praktilist lahendit. 
Vadja kirjaviisist ja sõnaloomest 14

\title{
6. Kokkuvõte
}

Enne soome-ugri teadusliku transkriptsiooni kasutuselevõttu on vadja keelt kirja pandud mitmeti. Kirjaviis on sõltunud eelkõige kirjutaja rahvusest. Transkriptsiooninüanssidest on loobutud mitmeköitelises „Vadja keele sõnaraamatus”. Selle põhimõtetest esineb siinkirjutaja rohkem tulevikku sihitud kirjaviis vaid mõne elemendi poolest (peamiselt $c, \check{c}$ ja sandhi). Seni on vadja keeles ilmunud vaid üks kakskeelne ilukirjanduslik tekstikogu (2004), milles on kasutatud originaalset kirjaviisi. Selles leidub ebajärjekindlusi, mida käesolevas kirjutises on püütud siluda võimalikult foneemilises suunas. Lühidalt öeldes, kirjaviis olgu foneemiline ilma lausefoneetiliste joonteta. Normaalselt funktsioneerivas kirjakeeles tuleb vastavalt vajadusele luua ka uusi mõisteid nii liitmise kui ka sufiksite abil tuletamise teel. Loodetavasti tuleb kord aeg, mil hakatakse vadjalaste, nende järglaste ja huviliste poolt osutama vadja keeles kirjutatu vastu praegusest märksa suuremat tähelepanu.

\author{
Aadress: \\ Enn Ernits \\ Veterinaarmeditsiini ja loomakasvatuse instituut \\ Eesti Maaülikool \\ Kreutzwaldi 62 \\ 51014 Tartu \\ E-mail: ennernits@hot.ee
}

\section{Kirjandus}

Adler, Elna (1970) „Kommentaarid F. Tumanski ”Lühikesele sõnaraamatule”. Vadja sõnaloend". Teoses Öpik, Elina. Vadjalastest ja isuritest XVIII saj. lõpul. Etnograafilisi ja lingvistilisi materjale Fjodor Tumanski Peterburi kubermangu kirjelduses, 190-194. Toimetanud A. Viires. Tallinn: Valgus.

Agranat, Tat'jana B. (2007) Zapadnyj dialekt vodskogo jazyka. Unificirovannoe opisanie dialektov ural'skix jazykov. (Mitteilungen der Societas Uralo-Altaica, 26.) Moskva, Groningen. 
Ahlqvist, August (1856) Wotisk grammatik jemte språkprof och ordförteckning. (Acta (Societatis Scientiarum Fennicae, 5.) Helsingforsiae.

Ariste, Paul (1941) „Vadja keelenäiteid”. Tartu Ülikooli toimetused, B XLIX $_{6}, 1-92$. Tartu.

Ariste, Paul (1948) Vadja keele grammatika. (Nõukogude soome-ugri teadused 9.) Tartu: Teaduslik Kirjandus.

Ariste, Paul (1956) „Ühest vadja rahvalaulust”. Tartu Riikliku Ülikooli toimetised, 43, 89-99.

Ariste, Paul (1960) Vadjalaste laule. (Eesti NSV Teaduste Akadeemia Emakeele Seltsi toimetised, 3.) Tallinn.

Ariste, Paul (1986) Vadja rahvalaulud ja nende keel. (Eesti NSV Teaduste Akadeemia Emakeele Seltsi toimetised, 22.) Tallinn: Valgus.

Ariste, Paul (1977) „Korni keele velmamisest”. Keel ja Kirjandus, 20, 5, 294 295.

Ernits, Enn (2005) „Vadja keele varasemast murdeliigendusest ja hilisemast hääbumisest". Piirikultuuriq ja -keeleq, 76-90. Toimõndanuq Karl Pajusalu ja Jan Rahman. (Võro Instituudi toimõndusõq, 17.) Võro: Võro Instituut'.

Ernits, Enn (2006a) „Vadja liikumisest ja kirjakeelest”. Keel ja Kirjandus, 49; $1,83-85$.

Ernits, Enn (2006b) „Ob oboznačenii zvukov v vodskom literaturnom jazyke”. Linguistica Uralica, 42, 1, 1-9.

Haltsonen, Sulo (1957) „Runoretki Inkeriin v. 1853. Lisätietoja D. E. D. Europaeuksen runonkeruun historiaan". In Suomi, 107 4 , 1-68. Helsinki: Suomalaisen Kirjallissuuden Seura.

Haltsonen, Sulo (1958) „Lönnrotin keräämät vatjalaiset itkut”. - Virittäjä, 1958, 62, 2, 183-189.

Heinsoo, Heinike (2007) „Kuidas vadjalased mäletavad taimede nimetusi. Maamunaa tappab?" Õdagumeresoomõ kodo. Läänemeresoome kodu, 33-53 (Võro Instituudi toimõndusõq, 20.) Toimõndanuq Helen Koks ja Jan Rahman. Võro: Võro Instituut'.

Mustonen, O. A. F. (1883) „Muistoonpanoja Vatjan kielestä”. Virittäjä, 1883, $1,144-188$.

Reguly, Antal (1958) „Vatjalaismuistiinpanot (Aufzeichnungen über die Woten) 1841". Julkaissut Sulo Haltsonen. - Suomalais-Ugrilaisen Seuran aikakauskirja, 603. Helsinki: Suomalais-Ugrilainen Seura, 1958, 1-62.

SKVR IV = Suomen kansan vanhat runot IV. Keski-Inkerin ja Vatjalaiset runot 3. Toisinnot 2763-4807. Julkaissut Väinö Salminen. Helsinki: 
Suomalaisen Kirjallissuuden Seura, 1928 (Internetivariant: http://dbgw.finlit.fi/skvr/skvr.phtml. Vaadatud 12.08.2009).

Zaiceva, Nina, Mullonen, Maria (1991) Abekirj. Petroskoi: Karjala.

Tauli, Valter (1968) Keelekorralduse alused. (Eesti Teadusliku Seltsi Rootsi väljaanne, 4.) Uppsala: Vaba Eesti.

Tsvetkov, Dmitri (2008) Vadja keele grammatika. Koostanud ja toimetanud Jüri Viikberg. Tallinn: Eesti Keele Sihtasutus.

Vađđa kaazgõt. Vodskie skazki. Sostavlenie, obrabotka M. Muslimov, E. Kuznecova. Sankt-Peterburg: NRK, 2004.

VKS 1 = Vadja keele sõnaraamat, 1. Toimetanud Elna Adler ja Merle Lepik. Tallinn: AE „Signalet”, 1990.

VES = Võro-eesti synaraamat. Päält 15000 tähüssyna. Kokko pandnuq Jüvä Sullõv. (Võro Instituudi toimõndusõq, 12.) Tarto, Võro: Võro Intituut', 2002.

Winkler, Eberhard (1993) "Zu Trefurts wotischer Sprachprobe (1783)". Linguistica Uralica, 29, 1, 38-44.

Winkler, Eberhard (1997) Krewinisch. Zur Erschließung einer ausgestorbenen ostseefinnischen Sprachform. (Veröffentlichungen der Societas UraloAltaica, 49.) Wiesbaden: Harrassowitz.

Öpik, Elina (1970) Vadjalastest ja isuritest XVIII saj. lõpul. Etnograafilisi ja lingvistilisi materjale Fjodor Tumanski Peterburi kubermangu kirjelduses. Toimetanud A. Viires. Tallinn: Valgus. 
Vadja kirjaviisist ja sõnaloomest 17 